\title{
The relationship between EI Niño Southern Oscillation (ENSO) and oceanographic parameters in North Sulawesi waters
}

\author{
Indonesian title: \\ Hubungan antara El Niño Southern Oscillation (ENSO) dan parameter oseanografi \\ di perairan Sulawesi Utara
}

\author{
Astrid Y. Lasut ${ }^{1 *}$, Wilhelmina Patty ${ }^{2}$, Veibe Warouw ${ }^{2}$, Calvyn A. Sondakh ${ }^{2}$, Robert A. Bara ${ }^{1}$, \\ Alfret Luasunaung ${ }^{2}$, Deiske A. Sumilat ${ }^{1}$

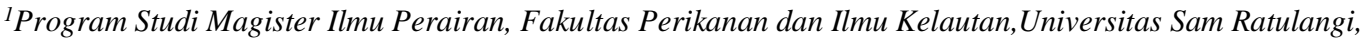 \\ Jl. Kampus Unsrat Bahu, Manado 95115 Sulawesi Utara, Indonesia \\ ${ }^{2}$ Fakultas Perikanan dan Ilmu Kelautan, Universitas Sam Ratulangi, Jl. Kampus Unsrat Bahu, \\ Manado 95115, Sulawesi Utara, Indonesia \\ *Corresponding author: astridyesicaa@gmail.com
}

Received: 28 January 2021 - Revised: 12 March 2021 - Accepted: 14 March 2021

\begin{abstract}
Information about oceanographic conditions is important to determine the fertility level of waters. Oceanographic parameters in water can be influenced by global climate factors, one of them is the ENSO (El Niño Southern Oscillation) phenomenon. There have been many studies on the effect of ENSO phenomenon on oceanographic variability, but no studies have been carried out in the waters of North Sulawesi. This study aims to determine the effect of the ENSO phenomenon on the variability distribution of oceanographic parameters in North Sulawesi waters. The data used for this study were Sea Surface Temperature (SST) and chlorophyll-a from the AQUA-MODIS imaging results, wind reanalysis results from ECMWF, and Nino 3.4 index as an indicator of ENSO from NOAA. The data were processed and analyzed using quantitative analysis methods in the form of graphics. The results showed an indirect effect of the ENSO phenomenon on SST parameters and chlorophyll-a. This is because the effect of the ENSO phenomenon occurred in a certain period: when strong El Niño triggered low temperatures of sea surface and high chlorophyll-a, and when La Niña was strong it triggered high temperatures of sea surface and low chlorophyll-a. Meanwhile, the wind speed pattern showed an insignificant effect because the wind speed was still dominated by the influence of the monsoon pattern.
\end{abstract}

Keywords: sea surface temperature; chlorophyll-a; wind speed; ENSO; El Niño; La Niña

\section{PENDAHULUAN}

Perairan Sulawesi Utara termasuk wilayah dengan massa air yang dipengaruhi oleh Samudera Pasifik. Hal ini terjadi, karena Laut Sulawesi dan Laut Maluku yang mengelilingi perairan tersebut merupakan pintu gerbang masuknya massa air dari Samudera Pasifik ke perairan Sulawesi dan perairan lainnya. Oleh karena posisinya berada di wilayah Indo-Pasifik Tropis, maka kawasan pesisir dan laut di wilayah tersebut menunjukkan keanekaragaman hayati (biodiversity) yang tinggi (Patty, 2015).

Variabilitas faktor oseanografi di suatu perairan berhubungan dengan tingkat kesuburan perairan, yang dapat di deteksi melalui beberapa parameter oseanografi, misalnya suhu permukaan laut, klorofil- $a$, dan angin. Variabilitas iklim global, seperti fenomena El Niño Southern Oscillation (ENSO), dapat mempengaruhi kondisi oseanografi suatu perairan (Seprianto et al., 2016). Variasi parameter oseanografi yang diamati selama terjadinya peristiwa El Niño ialah perubahan suhu dan struktur vertikal suhu permukaan laut, khususnya di wilayah pesisir, serta perubahan arus upwelling (Fadlan, 2015).

Fenomena ENSO merupakan fenomena yang terbentuk akibat adanya anomali suhu permukaan laut di wilayah Samudera Pasifik Ekuator (Fadlan et al., 2017). Fluktuasi ENSO terdiri dari tiga fenomena, yaitu kondisi normal, El Niño dan La Niña 


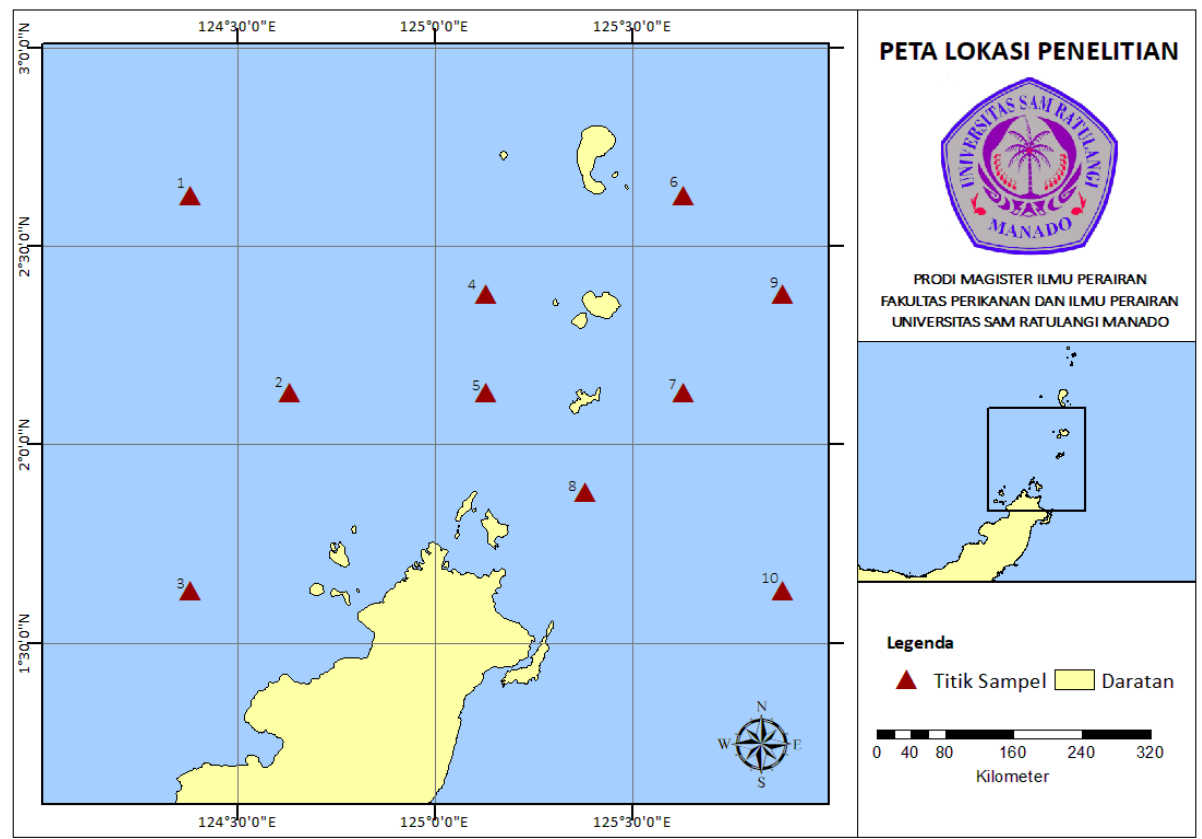

Gambar 1. Lokasi titik stasiun pengambilan sampel (data)

(Aldrian, 2008). Berdasarkan indeks Nino 3.4 dengan memakai standar nilai indeks $\pm 0.5{ }^{\circ} \mathrm{C}$ (Nurkhairani et al., 2018), maka fenomena ENSO dapat digolongkan dalam 3 kelompok, yakni kondisi normal (nilai indeks diantara $-0,5{ }^{\circ} \mathrm{C}$ hingga $+0,5$ ${ }^{\circ} \mathrm{C}$ ), El Niño (nilai indeks lebih dari $+0,5^{\circ} \mathrm{C}$ ), dan $L a$ Niña (nilai indeks kurang dari $-0,5^{\circ} \mathrm{C}$ ).

Sehubungan dengan fenomena ENSO, penelitian ini bertujuan untuk menganalisis pengaruh fenomena tersebut terhadap parameter oseanografi yang berhubungan dengan kesuburan perairan di wilayah perairan Sulawesi Utara.

\section{MATERIAL DAN METODE}

\section{Waktu dan Lokasi Penelitian}

Wilayah yang menjadi lokasi penelitan, yaitu perairan Sulawesi Utara pada posisi koordinat $124^{\circ}$ $00^{\prime}$ BT $-126^{\circ} 0^{\prime}$ BT dan $1^{\circ} 00^{\prime}$ LU-3 $00^{\prime}$ LU (Gambar 1). Periode data yang digunakan dalam penelitian ini mengikuti periode ENSO, yakni mulai Desember 2014 sampai dengan November 2019. Sepuluh stasiun pengumpulan data parameter oseanografi ditentukan secara acak. Posisi titik pengumpulan data tersebut dikelompokan ke dalam 2 wilayah, yakni Wilayah Barat dan Timur (Tabel 1).

\section{Jenis dan Teknik Pengumpulan Data}

Jenis data yang dikumpul, yaitu 1) Citra AQUA-MODIS level $4 \mathrm{~km}$ dengan resolusi $0,25^{\circ} \mathrm{x}$ $0,25^{\circ}$ dan komposit harian untuk parameter suhu permukaan laut (SPL) dan klorofil- $a$; 2) komposit harian kecepatan angin, yang merupakan hasil analisis kembali antara komponen $\mathrm{U}$ (zonal) dan $\mathrm{V}$ (meridional), dengan resolusi $0,25^{\circ} \times 0,25^{\circ}$; dan 3 ) indeks Nino 3.4.

Data dikumpulkan dengan cara sebagai berikut: 1) data SPL dan klorofil- $a$ diunduh dari Website Marine Copernicus (https://resources. marine.copernicus.eu); 2) data komposit harian kecepatan angin diunduh dari Website European Center for Medium-Range Weather Forecasts (ECMWF) (https://cds.climate.copernicus.eu/); 3) fenomena ENSO dipantau menggunakan data indeks anomali suhu nino 3.4, yang diunduh dari Website NOAA (https://origin.cpc.ncep.noaa.gov/).

\section{Analisis Data}

Data citra SPL, klorofil- $a$, dan rerata kecepatan angin harian diekstrak menggunakan software ODV (Ocean Data View) di mana menghasilkan data

Tabel 1. Titik stasiun pengambilan sampel (data)

\begin{tabular}{ccc}
\hline $\begin{array}{c}\text { Titik } \\
\text { Stasiun }\end{array}$ & Lintang & Bujur \\
\hline 1 & $2,63^{\circ} \mathrm{LU}$ & $124,38^{\circ} \mathrm{BT}$ \\
2 & $2,13^{\circ} \mathrm{LU}$ & $124,63^{\circ} \mathrm{BT}$ \\
3 & $1,63^{\circ} \mathrm{LU}$ & $124,38^{\circ} \mathrm{BT}$ \\
4 & $2,38^{\circ} \mathrm{LU}$ & $125,13^{\circ} \mathrm{BT}$ \\
5 & $2,13^{\circ} \mathrm{LU}$ & $125,13^{\circ} \mathrm{BT}$ \\
6 & $2,63^{\circ} \mathrm{LU}$ & $125,63^{\circ} \mathrm{BT}$ \\
7 & $2,13^{\circ} \mathrm{LU}$ & $125,63^{\circ} \mathrm{BT}$ \\
8 & $1,88^{\circ} \mathrm{LU}$ & $125,38^{\circ} \mathrm{BT}$ \\
9 & $2,38^{\circ} \mathrm{LU}$ & $125,88^{\circ} \mathrm{BT}$ \\
10 & $1,63^{\circ} \mathrm{LU}$ & $125,88^{\circ} \mathrm{BT}$ \\
\hline
\end{tabular}


dengan format teks $(*$.txt), yang selanjutnya diubah lagi ke format (*.csv) secara manual agar dengan mudah diolah menggunakan aplikasi Microsoft Excel.

Untuk nilai resultan angin didapatkan dari nilai kecepatan angin komponen $\mathrm{U}$ dan $\mathrm{V}$. Nilai kecepatan resultan angin (Utami et al., 2018) didapat dari persamaan sebagai berikut:

Keterangan:

$$
C=\sqrt{(u)^{2}+(v)^{2}}
$$

$C=$ kecepatan resultan angin $(\mathrm{m} / \mathrm{s})$

$u=$ kec. angin dalam arah Timur-Barat

$v=$ kec. angin dalam arah Utara-Selatan

Data dianaliss menurut stasiun dan wilayah pengumpulan data. Data dari masing-masing parameter yang dianalisis merupakan nilai rerata periode bulan. Korelasi antara parameter oseanografi (SPL, klorofil- $a$, dan angin) menurut fenomena ENSO dianalisis secara kuantitatif.

\section{HASIL DAN PEMBAHASAN}

Distribusi dan kelimpahan sumber daya hayati di suatu perairan tidak terlepas dari kondisi dan variasi parameter oseanografi pada perarian tersebut (Prasetyo and Suwarso, 2010). Di antara begitu banyak parameter oseanografi, SPL merupakan salah satu parameter penting untuk mempelajari variasi musim, fenomena iklim, seperti El Niño, dan juga Indian Ocean Dipole (IOD) (Cahya et al., 2016; Aryanti et al., 2019).

Perairan Indonesia memiliki beberapa karakteristik yang dipengaruhi oleh pergerakan angin monsun yang menyebabkan pergerakan arus dan angin yang berbeda. Perbandingan waktu, seperti musim Barat dan Timur, dilakukan untuk membandingkan sebaran SPL di Indonesia (Cahya et al., 2016).

\section{Hubungan SPL dengan Fenomena ENSO}

Berdasarkan data bulanan pada periode Desember 2014-November 2019, nilai suhu permukaan laut di wilayah Barat berkisar antara 28$30,5^{\circ} \mathrm{C}$ (Gambar 2). Pada saat periode El Niño, nilai rerata suhu cenderung lebih dingin. Nilai SPL terhangat (mencapai $30,29{ }^{\circ} \mathrm{C}$ ) terjadi di bulan November 2019 dan terendah (mencapai $27,88^{\circ} \mathrm{C}$ ) di bulan Februari 2019 (Tabel 2).

Pada saat periode La Niña, nilai rerata suhu cenderung lebih hangat; nilai suhu terhangat (mencapai 30,4 ${ }^{\circ} \mathrm{C}$ ) terjadi pada bulan Oktober 2017 dan terendah (mencapai $28,53{ }^{\circ} \mathrm{C}$ ) terjadi pada bulan Januari 2018 (Tabel 2). Pada saat kondisi normal, nilai suhu terhangat (mencapai $30,41{ }^{\circ} \mathrm{C}$ ) terjadi pada bulan Mei 2017 dan terendah (mencapai 27,98 ${ }^{\circ} \mathrm{C}$ ) terjadi pada bulan Februari 2017 (Tabel 2).

Fluktuasi nilai suhu permukaan laut di wilayah Timur, secara umum, menunjukkan variasi yang tidak signifikan dan cenderung konstan dengan kisaran $27-30{ }^{\circ} \mathrm{C}$ (Gambar 3). Pada saat periode $E l$ Niño, suhu permukaan mencapai $30,09{ }^{\circ} \mathrm{C}$ pada bulan November 2019 dan terendah (mencapai 26,79 ${ }^{\circ} \mathrm{C}$ ) pada bulan Agustus 2019 (Tabel 2). Pada saat periode La Niña, suhu terhangat (mencapai $30,11^{\circ} \mathrm{C}$ ) pada bulan Oktober 2017 dan terdingin (mencapai $28,49{ }^{\circ} \mathrm{C}$ ) pada bulan Januari 2018 (Tabel 2). Pada kondisi normal, suhu terhangat (mencapai $30,1{ }^{\circ} \mathrm{C}$ ) terjadi pada bulan Mei 2017 dan terdingin (mencapai 26,79 ${ }^{\circ} \mathrm{C}$ ) pada bulan Agustus 2019 (Tabel 2).

Secara umum, suhu permukaan air laut di perairan Sulawesi Utara untuk wilayah Barat dan Timur (Gambar 2 dan 3) relatif lebih rendah pada periode El Niño dibandingkan La Niña dan normal. Kondisi ini mendukung pernyataan Setyadji and Amri (2017), bahwa gejala ENSO membawa implikasi laut Indonesia lebih dingin pada kejadian El Niño dan lebih hangat pada kejadian La Niña. Hal ini terjadi, karena pada saat terjadi El Niño, tekanan udara di Pasifik Timur rendah; akibatnya, angin dan kolom air hangat dari Pasifik Barat mengalir ke Pasifik Timur. Kejadian ini membawa dampak suhu dan paras muka laut di Pasifik Barat turun (Tjasyono, 2003 dalam Putra et al., 2017).

Pada saat El Niño, terjadi penurunan volume massa air yang bergerak dari Samudra Pasifik ke Samudra Hindia. Kekosongan massa air di wilayah perairan Indonesia tersebut kemudian mendorong terjadinya upwelling, yakni naiknya massa air laut dalam dengan ciri temperatur rendah, salinitas tinggi, dan kaya akan nutrien, sehingga meningkatkan jumlah klorofil di perairan yang dapat meningkatkan kesuburan perairan (Safitri et al., 2012).

\section{Hubungan Klorofil- $a$ dengan Fenomena ENSO}

Berdasarkan data bulanan pada periode Desember 2014-November 2019, nilai konsentrasi klorofil- $a$ di wilayah Barat, secara umum, menunjukkan variasi yang signifikan antar periode ENSO dengan rentang nilai antara $0,08-0,30 \mathrm{mg} / \mathrm{m}^{3}$ (Gambar 4). Pada saat periode El Niño, nilai konsentrasi klorofil- $a$ cenderung lebih tinggi dan memiliki frekuensi konsentrasi lebih banyak dibandingkan periode lainnya. Nilai konsentrasi klorofil- $a$ tertinggi (mencapai $0,2703 \mathrm{mg} / \mathrm{m}^{3}$ ) terjadi pada bulan Januari 2015, dan terendah (mencapai 0,0838 mg/m $\mathrm{m}^{3}$ ) pada bulan Mei 2015 (Tabel 3).

Pada saat periode La Niña, nilai konsentrasi klorofil- $a$ cenderung lebih rendah dan memiliki frekuensi konsentrasi yang tidak signifikan, sama seperti pada saat kondisi normal. Nilai konsentrasi 


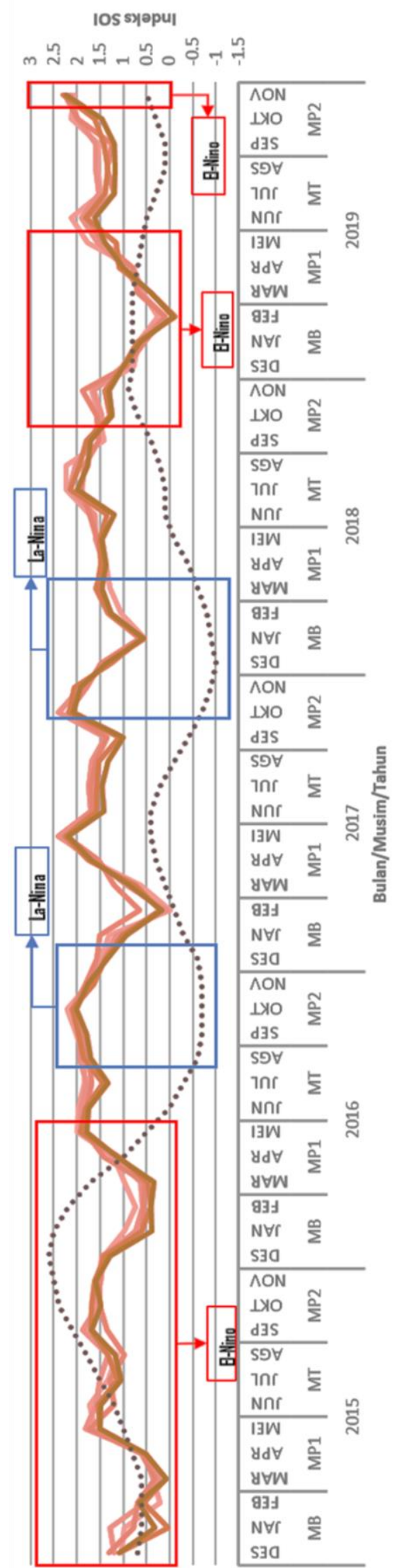

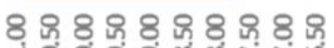

ส่

(ว.) nHกS

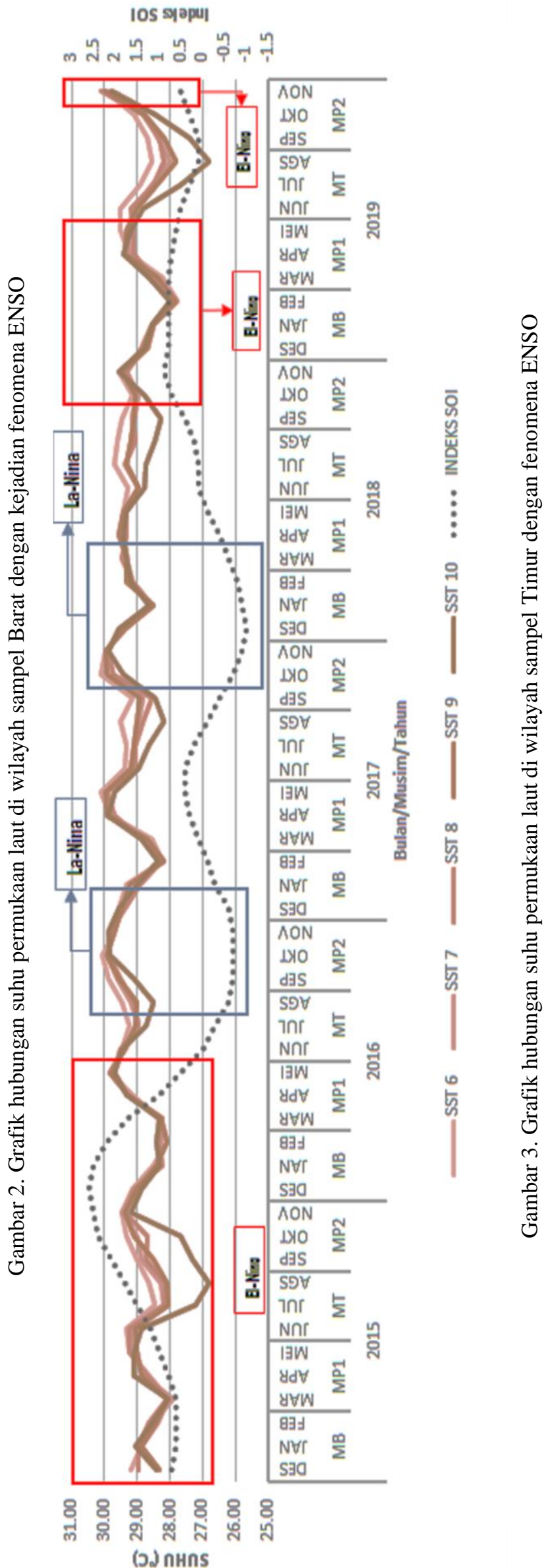


Lasut et al.: The relationship between El Niño Southern Oscillation (ENSO) and oceanographic ...

Tabel 2. Nilai variabilitas suhu permukaan laut saat kejadian fenomena ENSO

\begin{tabular}{ccccc}
\hline ENSO & \multicolumn{2}{c}{$\begin{array}{c}\text { Suhu di Wilayah Sampel Barat }\left({ }^{\circ} \mathrm{C}\right) \\
\text { Maksimum }\end{array}$} & $\begin{array}{c}\text { Suhu di Wilayah Sampel Timur }\left({ }^{\circ} \mathrm{C}\right) \\
\text { Maksimum }\end{array}$ & Minimum \\
\hline El Nino & 30.29 & 27.88 & 30.09 & 26.79 \\
La Nina & 30.40 & 28.53 & 30.11 & 28.49 \\
Netral & 30.41 & 27.98 & 30.10 & 26.79 \\
\hline
\end{tabular}

Tabel 3. Nilai variabilitas klorofil- $a$ saat kejadian fenomena ENSO

\begin{tabular}{|c|c|c|c|c|}
\hline \multirow{2}{*}{ ENSO } & \multicolumn{2}{|c|}{ Klorofil-a Wilayah Sampel Barat $\left(\mathrm{mg} / \mathrm{m}^{3}\right)$} & \multicolumn{2}{|c|}{ Klorofil-a Wilayah Sampel Timur $\left(\mathrm{mg} / \mathrm{m}^{3}\right)$} \\
\hline & Maksimum & Minimum & Maksimum & Minimum \\
\hline El Nino & 0.270 & 0.084 & 0.553 & 0.117 \\
\hline La Nina & 0.237 & 0.080 & 0.292 & 0.121 \\
\hline Netral & 0.251 & 0.097 & 0.475 & 0.127 \\
\hline
\end{tabular}

klorofil- $a$ tertinggi (mencapai $0,2368 \mathrm{mg} / \mathrm{m}^{3}$ ) terjadi pada bulan Februari 2018 dan terendah (mencapai $0,0801 \mathrm{mg} / \mathrm{m}^{3}$ ) terjadi pada bulan Oktober 2017 (Tabel 3). Pada saat periode normal, nilai konsentrasi klorofil- $a$ tertinggi (mencapai $0,2507 \mathrm{mg} / \mathrm{m}^{3}$ ) terjadi pada bulan Februari 2017, dan terendah (mencapai $0,0965 \mathrm{mg} / \mathrm{m}^{3}$ ) terjadi pada bulan Agustus 2017 (Tabel 3).

Variabilitas nilai konsentrasi klorofil- $a$ di wilayah Timur, secara umum, menunjukkan variasi yang tidak terlalu signifikan dan cenderung konstan selama periode ENSO dengan rentang nilai 0,10$0,60 \mathrm{mg} / \mathrm{m}^{3}$ (Gambar 5). Pada saat periode El Niño, nilai konsentrasi klorofil- $a$ tertinggi (mencapai $0,5525 \mathrm{mg} / \mathrm{m}^{3}$ ) terjadi pada bulan September 2015, dan terendah (mencapai $0,1169 \mathrm{mg} / \mathrm{m}^{3}$ ) pada bulan Mei 2015 (Tabel 3).

Pada saat periode La Niña, nilai konsentrasi klorofil- $a$ tertinggi (mencapai $0,2917 \mathrm{mg} / \mathrm{m}^{3}$ ) terjadi pada bulan Agustus 2016, dan terendah (mencapai $0,1214 \mathrm{mg} / \mathrm{m}^{3}$ ) terjadi pada bulan Oktober 2017 (Tabel 3). Pada saat periode normal, nilai konsentrasi klorofil- $a$ tertinggi (mencapai $0,4755 \mathrm{mg} / \mathrm{m}^{3}$ ) terjadi pada bulan Agustus 2019, dan terendah (mencapai $0,1269 \mathrm{mg} / \mathrm{m}^{3}$ ) terjadi pada bulan September 2017 (Tabel 3). Nampak, pola variasi nilai konsentrasi klorofil- $a$ pada saat periode El Niño lebih tinggi dibandingkan dengan periode La Niña dan periode normal.

Secara umum, nilai konsentrasi klorofil- $a$ di perairan Sulawesi Utara, di wilayah Barat dan Timur (Gambar 4 dan 5) cenderung lebih tinggi pada periode El Niño dibandingkan periode La Niña dan periode normal. Hal ini terjadi, karena pada periode El Niño, massa air hangat yang bergerak ke Timur menyebabkan kekosongan massa air di perairan Indonesia, termasuk perairan Sulawesi Utara, sehingga terjadi upwelling. Hal ini berbanding terbalik dengan kondisi La Niña dan normal, yaitu massa air hangat menumpuk di atas perairan Indonesia, yang menyebabkan terjadinya downwelling.

Menurut Natalia et al. (2015), massa air yang berasal dari perairan dalam, yang kaya akan nutrien, cenderung mengandung banyak fitoplankton, yang merupakan dasar dari rantai makanan di lautan. Perairan yang mengalami proses upwelling massa air merupakan perairan yang subur dan produktivitas primernya tinggi, karena mengandung banyak fitoplankton yang dapat mensuplai oksigen ke dalam kolom air.

\section{Hubungan Kecepatan Angin dengan Fenomena ENSO}

Rerata nilai kecepatan angin selama periode tahun 2015-2019 berada di rentang nilai 2,0-5,5 m/s (Gambar 6). Pada saat periode El Niño, nilai kecepatan angin tertinggi $(5,01 \mathrm{~m} / \mathrm{s})$ terjadi pada bulan Juli 2015, dan terendah $(2,45 \mathrm{~m} / \mathrm{s})$ terjadi pada bulan Mei 2019 (Tabel 4). Pada saat periode La Niña, nilai kecepatan angin tertinggi $(4,07 \mathrm{~m} / \mathrm{s})$ terjadi pada bulan Agustus 2016, dan terendah $(2,41 \mathrm{~m} / \mathrm{s})$ terjadi pada bulan November 2017 (Tabel 4). Pada saat periode normal, nilai kecepatan angin tertinggi $(5,09$ $\mathrm{m} / \mathrm{s}$ ) terjadi pada bulan Agustus 2019, dan terendah $(2,19 \mathrm{~m} / \mathrm{s})$ pada bulan Mei 2017 (Tabel 4).

Pada umumnya, nilai kecepatan angin di wilayah perairan Sulawesi Utara tidak mengalami perbedaan yang signifikan antara sisi Barat dan

Tabel 4. Nilai variabilitas kecepatan angin saat kejadian fenomena ENSO

\begin{tabular}{ccc}
\hline \multirow{2}{*}{ ENSO } & \multicolumn{2}{c}{ Kecepatan } \\
& Maksimum & $\begin{array}{c}\text { Angin }(\mathrm{s}) \\
\text { Minimum }\end{array}$ \\
\hline El Nino & 5.01 & 2.45 \\
La Nina & 4.07 & 2.41 \\
Netral & 5.09 & 2.19 \\
\hline
\end{tabular}


Aquatic Science \& Management, Vol. 9, No. 1 (April 2021)
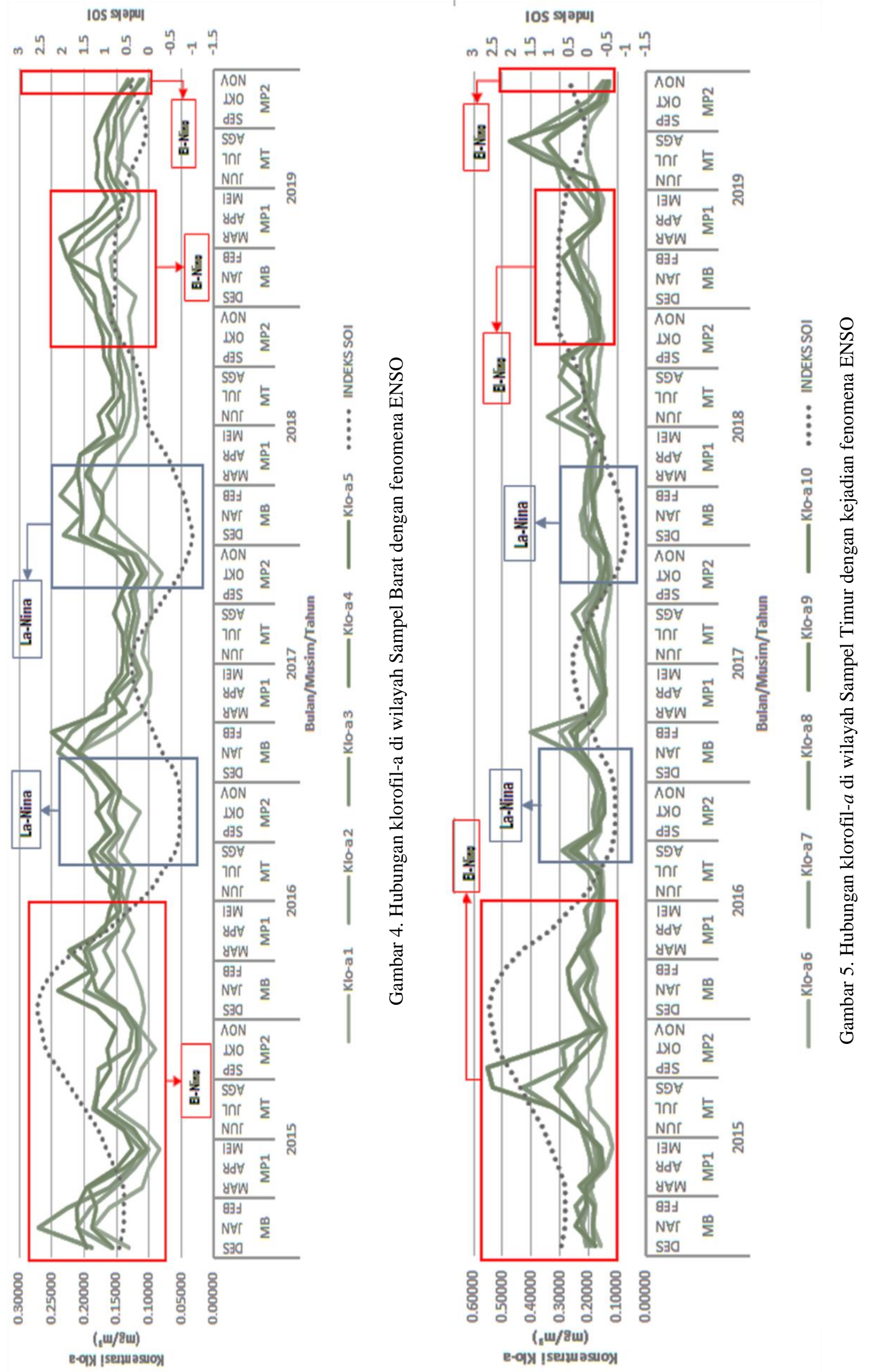
Lasut et al.: The relationship between El Niño Southern Oscillation (ENSO) and oceanographic ...

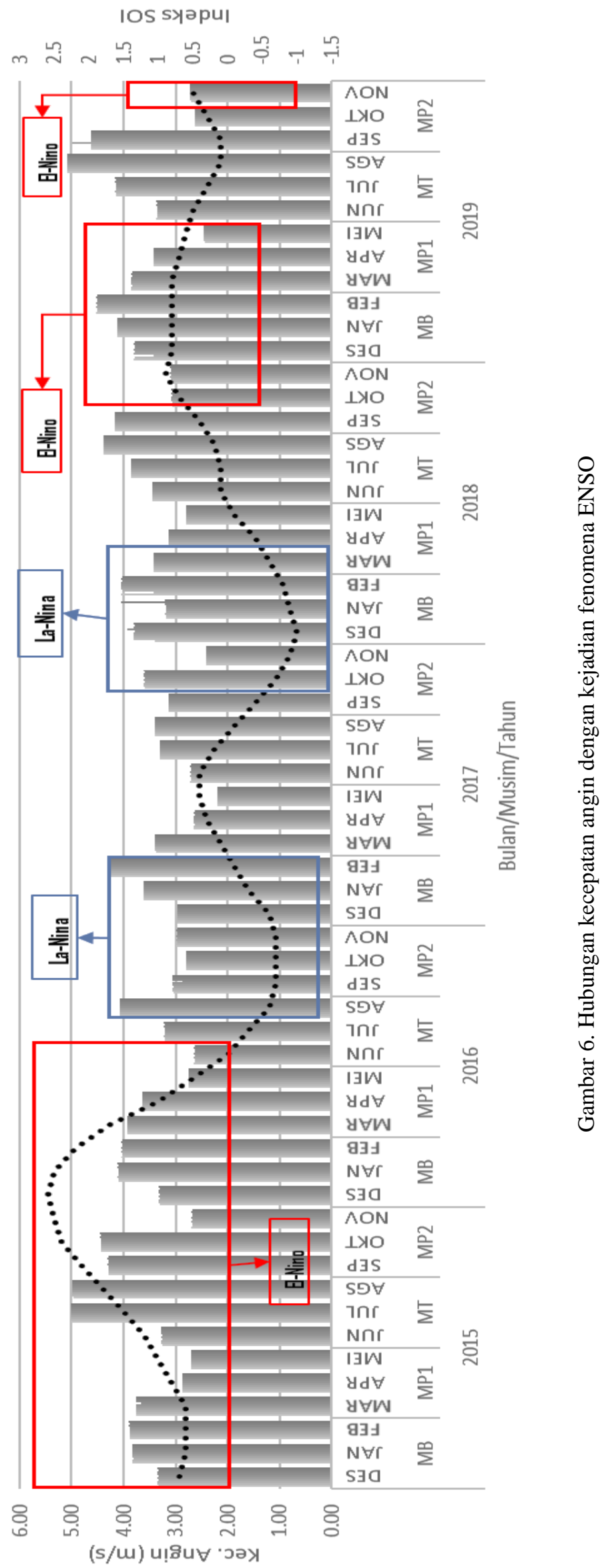


Timur. Hal ini terjadi, karena data kecepatan angin yang digunakan diukur pada ketinggian $10 \mathrm{~m}$ di atas permukaan laut. Menurut Wahid (2018), pada ketinggian $10 \mathrm{~m}$ ke atas, angin dianggap mendekati stabil karena nilai gradien menjadi semakin kecil. Oleh karena itu, analisis variabilitas nilai kecepatan angin di perairan Sulawesi Utara dijelaskan berdasarkan periode ENSO.

Secara umum, kecepatan angin permukaan di wilayah perairan Sulawesi (Gambar 6) cenderung lebih tinggi pada periode $E l$ Niño dan periode normal, dibandingkan pada periode La Niña. Peningkatan kecepatan angin ini disebabkan oleh perbedaan tekanan udara yang signifikan antara Samudera Pasifik Timur dan Samudera Pasifik Barat. Oleh karena sifat massa udara bergerak dari daerah yang memiliki tekanan udara tinggi menuju daerah yang memiliki tekanan lebih rendah, maka semakin tinggi selisih tekanan udara antara dua daerah, kecepatan gerak massa udara juga akan semakin tinggi (Utami et al., 2018). Dengan demikian, hal ini menunjukkan, pola kecepatan angin di wilayah perairan Sulawesi Utara tidak secara langsung dipengaruhi oleh fenomena ENSO melainkan dominan dipengaruhi oleh pola angin monsun.

Dalam analisis hubungan antara parameter SPL, klorofil- $a$, dan angin terhadap indeks ENSO, diperoleh hasil yang signifikan di wilayah perairan Sulawesi Utara, yang ditunjukkan oleh wilayah Barat dan Timur. Hal ini merupakan suatu kebaruan, yang dilakukan di perairan Sulawesi Utara.

\section{KESIMPULAN}

Fenomena ENSO berpengaruh secara tidak langsung pada SPL dan klorofil- $a$ di perairan Sulawesi Utara. Hal ini terjadi, karena pada beberapa periode tertentu, El Niño dapat memicu SPL rendah dan klorofil-a tinggi, dan La Niña dapat memicu SPL tinggi dan klorofil- $a$ rendah. Pada saat fenomena ENSO terjadi, SPL dan klorofil- $a$ di wilayah Timur berpengaruh secara signifikan dibandingkan di wilayah Barat. Sedangkan kecepatan angin tidak menunjukkan pengaruh yang signifikan baik di wilayah Barat dan Timur, karena pola kecepatan angin masih dominan dipengaruhi oleh pola angin monsun.

Ucapan terima kasih. Penulis mengucapkan terima kasih kepada semua pihak yang telah membantu dalam pelaksanaan penelitian dan penulisan naskah hasil penelitian untuk publikasi dalam jurnal ilmiah. "Kami menyatakan bahwa tidak ada konflik kepentingan dengan organisasi manapun mengenai bahan yang didiskusikan dalam naskah ini”.

\section{REFERENSI}

ARYANTI, N.L.N., HENDRAWAN, I.G. and SUTEJA, Y. (2019) Studi variabilitas produktivitas primer bersih serta hubungannya dengan El-Nino Southern Oscillasion (ENSO) dan Indian Ocean Dipole (IOD) di Laut Banda berdasarkan data satelit Aqua Modis. Journal of Marine and Aquatic Sciences, 5 (1), 64-76.

ALDRIAN, E. (2008) Meteorologi Laut Indonesia. Jakarta: BMKG.

CAHYA, C.N., SETYOHADI, D. and SURINATI, D. (2016) Pengaruh parameter oseanografi terhadap distribusi ikan. Jurnal Oseana, 41 (4), 114.

FADLAN, A. (2015) El Niño dan La Niña. Unpublished Paper. Fakultas Perikanan dan Ilmu Kelautan. Semarang: Universitas Diponegoro.

FADLAN, A., SUGIANTO, D.N, KUNARSO and ZAINURI, M. (2017) Pengaruh fenomena monsun, El Niño Soithern Oscillation (ENSO) dan Indian Ocean Dipole (IOD) terhadap anomali tinggi muka laut di Utara dan Selatan Pulau Jawa. Prosiding Seminar Nasional Hasil-Hasil Penelitian Perikanan dan Kelautan Ke-VI, pp. 205-217.

NATALIA, E.H., KUNARSO and RIFAI, A. (2015) Variabilitas suhu permukaan laut dan klorofil-a kaitannya dengan El Niño Southern Oscillation (ENSO) dan Indian Ocean Dipole (IOD) pada periode upwelling 2010-2014 di Lautan Hindia (Perairan Cilacap). Jurnal Oseanografi, 4 (4), 661-669.

NURKHAIRANI, Y., SUPRIATNA and SUSILONINGTYAS (2018) Wilayah potensi ikan pelagis pada variasi kejadian ENSO dan normal di Selat Sunda. Jurnal Geografi Lingkungan Tropik, 2 (1), 52-63.

PATTY, S.I. (2015) Karakteristik fosfat, nitrat, dan oksigen terlarut di Perairan Selat Lembeh, Sulawesi Utara. Jurnal Pesisir dan Laut Tropis, 2 (1), 1-7.

PUTRA, D.P., AMIN, T. and ASRI, D.P. (2017) Analisis pengaruh IOD dan ENSO terhadap distribusi klorofil-a pada periode upwelling di Perairan Sumbawa Selatan. Jurnal Meteorologi Klimatologi dan Geofisikia, 4 (2), 7-16.

PRASETYO, A.P. and SUWARSO (2010) Produktifitas primer dan kelimpahan ikan layang (Decapterus spp.) hubungannya dengan feno- 
Lasut et al.: The relationship between El Niño Southern Oscillation (ENSO) and oceanographic ...

mena ENSO, di Selat Makassar bagian Selatan. Marine Fisheries, 1 (1), 47-56.

SAFITRI, M., CAHYARINI, S.Y. and PUTRI, M.R. (2012) Variasi arus Arlindo dan parameter oseanografi di Laut Timor sebagai indikasi kejadian ENSO. Jurnal Ilmu dan Teknologi Kelautan Tropis, 4 (2), 369-377.

SEPRIANTO, A., KUNARSO and WIRASATRIYA, A. (2016) Studi pengaruh El Niño Southern Oscillation (ENSO) dan Indian Ocean Dipole (IOD) terhadap variabilitas suhu permukaan laut dan klorofil-a di perairan Karimunjawa. Jurnal Oseanografi, 5 (4), 452-461.
SETYADJI, B. and AMRI, K. (2017) Pengaruh anomali iklim (ENSO dan IOD) terhadap sebaran ikan pedang (Xiphias gladius) di Samudera Hindia bagian Timur. Jurnal Segara, 13 (1), 4963.

UTAMI, I.R., JUMARANG, M.I. and APRIANSYAH (2018) Perhitungan potensi energi angin di Kalimantan Barat. Prisma Fisika, 4 (1), 65-69.

WAHID M. A. (2018) Mengidentifikasi besar kecepatan angin dan energinya melalui data Ncep/Ncar Reanalysis dan 5 Stasiun BMKG di Provinsi Aceh. Jurnal Phi-Jurnal Pendidikan Fisika dan Fisika Terapan, 1, 1-10. 